\title{
Of Older Mice and Men: Branched-Chain Amino Acids and Body Composition
}

\author{
Rosilene V. Ribeiro ${ }^{1,2, *,+} \mathbb{0}$, Samantha M. Solon-Biet ${ }^{1,2,3, *,+}$, Tamara Pulpitel ${ }^{1,2}$, \\ Alistair M. Senior 1,2, Victoria C. Cogger 2,3, Ximonie Clark ${ }^{1,2}$, John O'Sullivan 2,4, \\ Yen Chin Koay ${ }^{2,4}$, Vasant Hirani ${ }^{1,2,5}$, Fiona M. Blyth ${ }^{6}$, Markus J. Seibel ${ }^{3,6,7}$, \\ Louise M. Waite ${ }^{5}$, Vasi Naganathan ${ }^{6}$, Robert G. Cumming ${ }^{8,5}$, David J. Handelsman ${ }^{7}$, \\ Stephen J. Simpson ${ }^{1,2}$ and David G Le Couteur 1,2,3,9 \\ 1 School of Life and Environmental Sciences, Faculty of Science, The University of Sydney, \\ Sydney 2006, Australia \\ 2 Charles Perkins Centre, Camperdown, The University of Sydney, Sydney 2006, Australia \\ 3 Sydney Medical School, Faculty of Health and Medicine, The University of Sydney, Sydney 2006, Australia \\ 4 Heart Research Institute, The University of Sydney, Sydney 2006, Australia \\ 5 ARC Centre of Excellence in Population Ageing Research (CEPAR), Kensington 2033, Australia \\ 6 Concord Clinical School, Faculty of Health and Medicine, The University of Sydney, Concord 2139, Australia \\ 7 ANZAC Research Institute, The University of Sydney, Concord 2139, Australia \\ 8 School of Public Health, University of Sydney, Sydney 2006, Australia \\ 9 Ageing and Alzheimers Institute, Concord Hospital, University of Sydney, Concord 2139, Australia \\ * Correspondence: rosie.ribeiro@sydney.edu.au (R.V.R.); samantha.biet@sydney.edu.au (S.M.S.-B.) \\ $\dagger$ These two authors contribute equally to this paper.
}

Received: 22 July 2019; Accepted: 6 August 2019; Published: 13 August 2019

\begin{abstract}
Protein and branched-chain amino acid (BCAA) intake are associated with changes in circulating BCAAs and influence metabolic health in humans and rodents. However, the relationship between BCAAs and body composition in both species is unclear, with many studies questioning the translatability of preclinical findings to humans. Here, we assessed and directly compared the relationship between circulating BCAAs, body composition, and intake in older mice and men. Body weight and body fat were positively associated with circulating BCAA levels in both mouse and human, which remained significant after adjustments for age, physical activity, number of morbidities, smoking status, and source of income in the human cohort. Macronutrient intakes were similarly associated with circulating BCAA levels; however, the relationship between protein intake and BCAAs were more pronounced in the mice. These findings indicate that the relationship between circulating BCAAs, body composition, and intakes are comparable in both species, suggesting that the mouse is an effective model for examining the effects of BCAAs on body composition in older humans.
\end{abstract}

Keywords: branched-chain amino acids; body composition; ageing; mice; humans

\section{Introduction}

Branched-chain amino acids (BCAAs; valine, leucine, isoleucine) have been linked to the development of type 2 diabetes, insulin resistance, and obesity in both rodents and humans [1-5]. It is unclear whether this association is a direct reflection of the diet, or the consequence of systemic metabolic derangement $[3,6,7]$. In mice, increasing intake of proteins and BCAAs is associated with both elevated circulating BCAA levels and changes in body composition $[3,4,6,8]$. In humans, however, the link between dietary BCAAs and health is less clear. While some studies linking high circulating levels of BCAAs with metabolic dysregulation also show increases in total protein and/or BCAA 
intake [1,2,9-11], other observational studies report conflicting evidence, with some showing positive, negative, or neutral effects of dietary protein and/or BCAAs on health [12,13].

Therefore, the question of how closely the relationship between diet, BCAAs, and body composition in rodents reflect the relationship in humans is an important issue to resolve. In animal studies, elucidating the relationship between diet, circulating BCAAs, and body composition can be uniquely informative, controlling for various factors that could not otherwise be achieved in a free-living human population. However, translating these findings in order to humans to better understand the role of BCAAs in health requires that key outcomes in both rodents and humans respond similarly.

Here, we directly compare the relationship between circulating BCAAs, energy and macronutrient intake, and body composition in a group of men aged over 75 years with a cohort of older mice at 15 months of age. We show that the relationship between circulating BCAAs, intake, and body composition were comparable across both free-living humans and mice under tightly controlled dietary manipulations, suggesting that preclinical findings in mice may reliably inform studies examining the link between BCAAs and body composition in humans.

\section{Materials and Methods}

\subsection{Human Cohort}

\subsubsection{Study Design}

The Concord Health and Ageing in Men Project (CHAMP) is a longitudinal cohort study investigating the health of older men based in Sydney, Australia. The recruitment, which is described elsewhere [14], involved a defined urban region (the Local Government Areas of Burwood, Canada Bay, and Strathfield near Concord Hospital in Sydney, Australia) sampled using the New South Wales Electoral Roll. A total of 1705 men participated in the initial study wave in 2005-2006 [14]. Dietary data were assessed through diet history interviews at the third wave (five-year follow-up, 2012). At the five-year follow-up, 954 participants completed questionnaires and clinical assessments, and of those, 794 completed diet history interviews. CHAMP was approved by the Sydney South West Area Health Service Human Ethics Committee, Concord Repatriation General Hospital, Sydney, Australia (Protocol number HREC/10/CRGH/28). Written consent was obtained from all participants and the study was conducted in accordance with the World Medical Association Helsinki Declaration.

\subsubsection{Dietary Data}

Details about CHAMP dietary data collection and validation have been previously described [15]. Briefly, usual dietary intake (past 3 months) was assessed through diet history interviews [16]; those interviews followed a standardised protocol and were conducted at participants' residences by a trained dietitian. Validation of this method was obtained through comparison with a 4-day weighed food record collected in a subgroup $(n=56)$ of participants [17].

\subsubsection{Outcome Variables}

Body weight was measured according to a standardised protocol. All fasting blood tests were performed at the Diagnostic Pathology Unit of Concord RG Hospital, which is a National Australian Testing Authority (NATA) accredited pathology service, using a MODULAR Analytics system (Roche Diagnostics, Castle Hill, Australia). Amino acids were analysed at the Australian Proteome Analysis Facility, Macquarie University, using the Waters AccQ-Tag Ultra Chemistry Kit (Waters Corporation, Milford, MA, USA). Dual X-ray absorptiometry (DXA) using the fan beam Discovery-W scanner (Hologic Inc., Bedford, MA, USA) was used to obtain individuals' whole-body scans. Men removed jewellery and wore a light cotton gown free from metal. The head was excluded from all measures and lean mass was calculated as the difference between non-fat mass and bone mineral content. 


\subsubsection{Covariates}

Information on socio-demographic, lifestyle, and economic factors were obtained through a self-completed questionnaire. Activity level was determined through the Physical Activity Scale for the Elderly (PASE) [18]. Source of income was categorised as means-tested age pension only and other (repatriation pension, veteran's pension, superannuation or other private income, own business/farm/partnership, wage or salary, other or any source of income combination). Source of income was used as a proxy of personal income, assuming that age pensioners had the lowest income. Participants self-reported whether they have been diagnosed (by a doctor or a health care provider) with diabetes, thyroid problems, osteoporosis, Paget's disease, stroke, Parkinson's disease, kidney stones, dementia, depression, epilepsy, hypertension, myocardial infarction, angina, heart failure, intermittent claudication, chronic obstructive lung disease, liver disease, chronic kidney disease, arthritis, or cancer (excluding non-melanotic skin cancer and benign tumours such as bowel polyps and meningioma), and number of morbidities was calculated as the sum of diagnosed conditions.

\subsection{Mouse Cohort}

\subsubsection{Animals and Husbandry}

A total of 384 C57BL/6J mice of both sexes were purchased from the Animal Resource Centre (Perth, WA) at 3 weeks old. Mice were group-housed in cages of four on a $12 \mathrm{~h} \mathrm{light-dark} \mathrm{cycle} \mathrm{at} \mathrm{the}$ Charles Perkins Centre at the University of Sydney. Mice were housed at $22-24{ }^{\circ} \mathrm{C}$ and were given ad libitum access to food and water. At 12 weeks of age, mice were randomly allocated to one of four experimental diets, monitored weekly, with food and body weights recorded bi-weekly until 6 months of age, and monthly thereafter. Animals remained on allocated diets throughout their lifetime. At 15 months of age, one mouse from each cage was sacrificed with tissues and blood collected for analysis ( $n=12$ males and 12 females). For comparisons between BCAAs and body composition, 19-23 mice per diet treatment were analysed. Data relating to cardiometabolic health and brain ageing have been published previously [19]. Experiments were approved by the University of Sydney's Animal Ethics Committee (protocol no. 2014/752).

\subsubsection{Experimental Diets}

Four experimental diets were designed and manufactured in dry-pelleted form by Specialty Feeds (Perth, Australia). Diets had the same energy density $(14.4 \mathrm{~kJ} / \mathrm{g}$ ), were matched in net metabolizable energy from fat $(18 \%)$, but varied in protein $(\mathrm{P})$ and carbohydrate $(\mathrm{C})$ content. Diets consisted of either $5 \% \mathrm{P}$ and $77 \%$ C, $10 \% \mathrm{P}$ and $72 \%$ C, $15 \% \mathrm{P}$ and $67 \% \mathrm{C}$, or $19 \% \mathrm{P}$ and $63 \% \mathrm{C}$. Diets were based on the rodent diet AIN-93G and formulated to contain all essential vitamins, minerals, and amino acids for growth in mice. Casein was the primary protein component, the main carbohydrate component was wheatstarch, and the main fat component was soy oil.

\subsubsection{Outcome Variables}

Body composition and plasma amino acids were assessed in each mouse at 15 months of age. Body composition was assessed by EchoMRI (EchoMRI 900, Houston, TX, USA). Fat mass (g) and lean mass $(\mathrm{g})$ were measured for each mouse and \% body fat and \% body lean calculated. Free amino acids were quantified in plasma. Targeted LC-QQQ-MS analysis was employed to detect metabolites. Metabolomic analysis was conducted using a tandem liquid chromatography-mass spectrometry (LC-MS/MS) system (Agilent 1260 Infinity liquid chromatography coupled to a QTRAP 5500 mass spectrometer (AB SCIEX, Framingham, USA). A hydrophilic interaction chromatography (HILIC) column was used for the detection of BCAAs. All raw data files (Analyst software, version 1.6.2; AB Sciex, Foster City, CA, USA) were imported into Multi-QuantTM 3.0 Software for MRM Q1/Q3 peak integration. A detailed description of metabolite profiling is described by $\mathrm{O}^{\prime}$ Sullivan, et al. $[6,20]$. 


\subsubsection{Statistical Analyses}

Data were analysed in R (v.3.4.1, R Foundation for Statistical Computing, Vienna, Austria) and significance considered when $p<0.05$. Data from males and females were combined to analyse various outcomes in mice. Regression analyses were performed using the $l m$ function in the base package [21,22]. Univariate analyses were performed to investigate the associations between circulating BCAAs, energy and macronutrient intake, and body composition variables. Two sample $t$-tests were performed to assess the mean difference between categorical variables (income and smoking status). Linear regressions were used to investigate the association between BCAA, age, physical activity level, and number of comorbidities. Subsequently, multivariate analyses were performed to adjust firstly for age and then for all factors commonly associated with dietary intake and circulating BCAA levels in humans. Correlation matrices were generated in R using the "corrplot" package [23].

\section{Results}

The human cohort characteristics have been described elsewhere $[15,23]$. Briefly, the mean age was 81.3 years $(\mathrm{SD}=4.6)$, body weight was $78.0 \mathrm{~kg}(\mathrm{SD}=12.78)$, fat mass $21.6 \mathrm{~kg}(\mathrm{SD}=7.22)$, percentage fat $29.5 \%(\mathrm{SD}=6.06)$, lean mass $47.8 \mathrm{~kg}(\mathrm{SD}=6.24)$, percentage lean $67.6 \%(\mathrm{SD}=5.90)$, and the majority of participants were non-smokers $(96 \%)$, did not rely on the age pension as sole source of income $(59 \%)$, and had at least two comorbidities. A total of 83 mice were analysed to determine the relationship of BCAAs with body composition. Mean body weight was $40.5 \mathrm{~g}(\mathrm{SD}=7.81)$, fat mass $14.0 \mathrm{~g}(\mathrm{SD}=5.59)$, percentage fat $33.4 \%(\mathrm{SD}=9.37)$, lean mass $24.1 \mathrm{~g}(\mathrm{SD}=3.74)$ and percentage lean $60.5 \%(\mathrm{SD}=8.79)$.

\subsection{Circulating BCAAs and Body Composition}

In humans, circulating BCAA levels significantly decreased with age $(p<0.001$, Supplementary Materials, Figure S1). Body weight, fat, and lean mass as well as percentage body fat were positively associated with circulating BCAAs, whereas percentage body lean mass was negatively associated with BCAAs in both the human cohort and mice model, with stronger correlation in mice (Figure 1). After adjustment for age, physical activity, number of morbidities, smoking status, and source of income, the association between circulating BCAAs and all body composition measures remained statistically significant in the human cohort (Table 1). Individual BCAAs were also correlated with body composition variables in Figure 1F,L. We found that all outcomes, except for \% body lean, were positively correlated with valine, isoleucine, and leucine-a result consistent in both mice and men. 


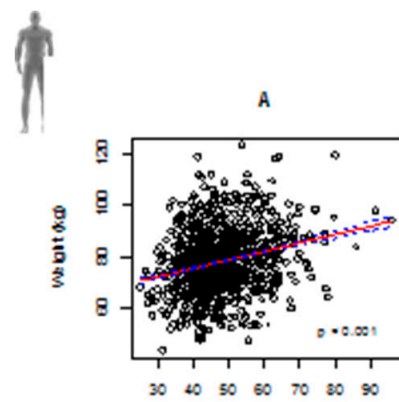

sors

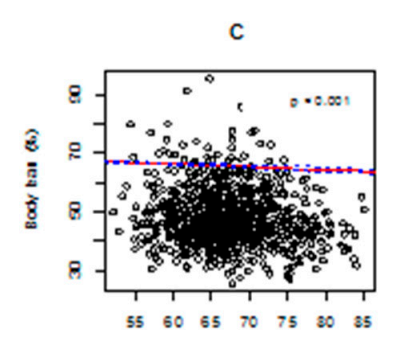

sors

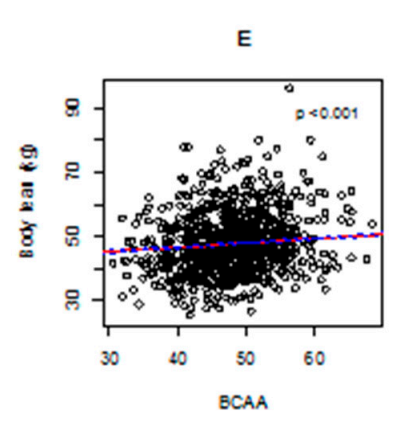

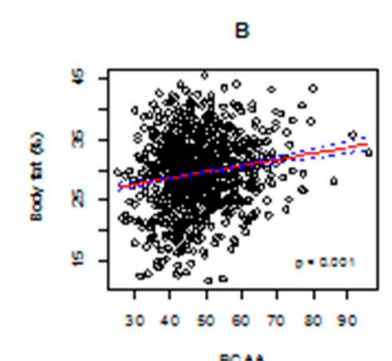

scen

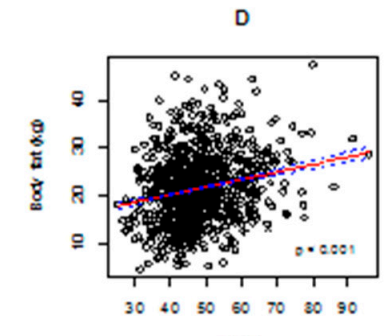

$B C M$

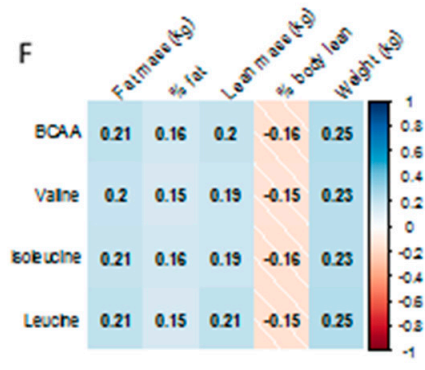

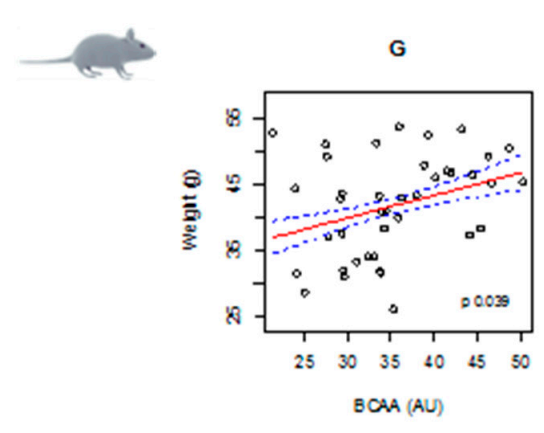
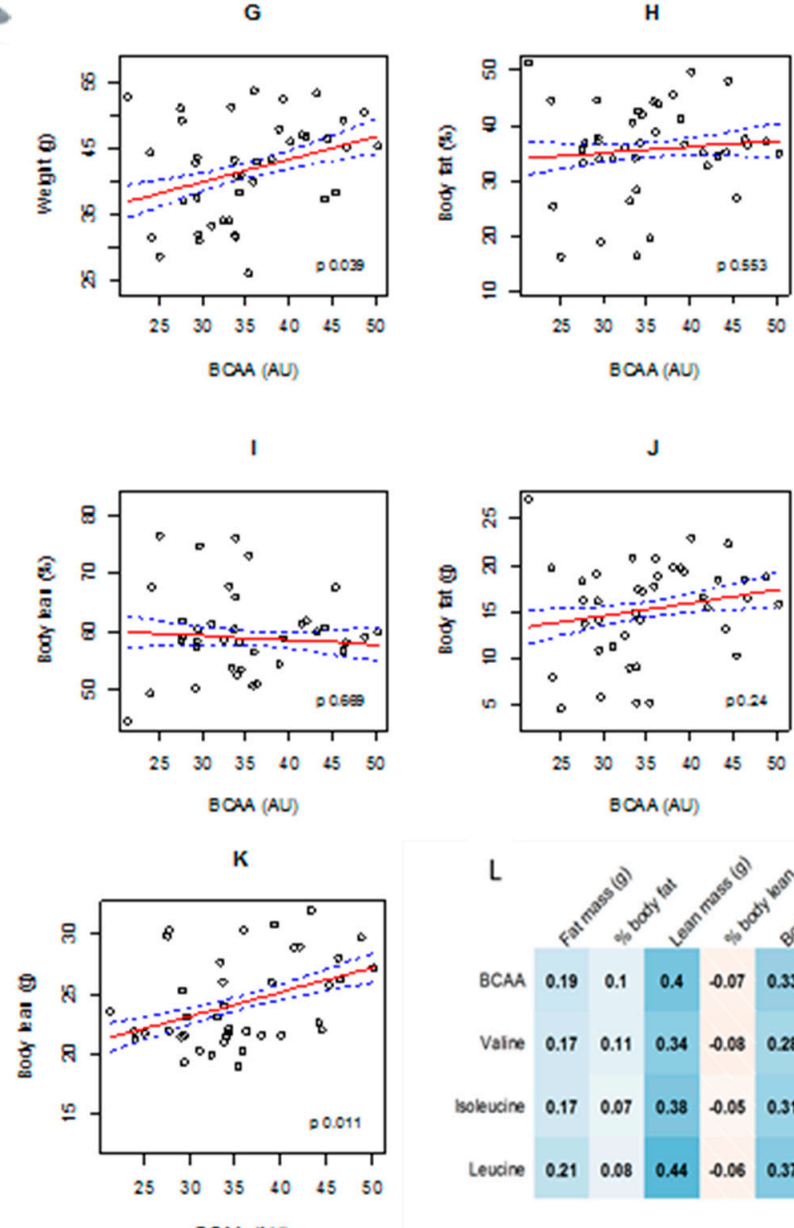

Figure 1. Circulating branched chain amino acids (BCAAs) and body composition in older men and mice. Red lines represent fitted values and blue dotted lines represent $95 \%$ confidence intervals. Body weight $(\mathrm{kg})$, body fat $(\%$ and $\mathrm{kg})$, and body lean $(\%$ and $\mathrm{kg})$ were significantly associated with circulating BCAAs in men $(\mathbf{A}-\mathbf{F})$ and mice $(\mathbf{G}-\mathbf{L})$. Correlation matrices show similar results in both men $(\mathbf{F})$ and mice $(\mathbf{L})$ : Energy, protein, and fat intake passively correlated with BCAAs whereas carbohydrate negatively correlated with BCAAs. 
Table 1. Regression coefficients (and SE) for change in body composition and macronutrient intake per unit of BCAA.

\begin{tabular}{|c|c|c|}
\hline HUMANS & & \\
\hline Fat mass (kg) & $\beta$ (SE) & $p$ \\
\hline Model 1 & $0.16(0.02)$ & $<0.001$ \\
\hline Model 2 & $0.15(0.03)$ & $<0.001$ \\
\hline Model 3 & $0.15(0.03)$ & $<0.001$ \\
\hline \multicolumn{3}{|l|}{ Body fat (\%) } \\
\hline Model 1 & $0.10(0.02)$ & $<0.001$ \\
\hline Model 2 & $0.10(0.02)$ & $<0.001$ \\
\hline Model 3 & $0.10(0.02)$ & $<0.001$ \\
\hline \multicolumn{3}{|l|}{ Lean mass (kg) } \\
\hline Model 1 & $0.13(0.02)$ & $<0.001$ \\
\hline Model 2 & $0.10(0.02)$ & $<0.001$ \\
\hline Model 3 & $0.11(0.02)$ & $<0.001$ \\
\hline \multicolumn{3}{|l|}{ Body lean (\%) } \\
\hline Model 1 & $-0.10(0.02)$ & $<0.001$ \\
\hline Model 2 & $-0.10(0.02)$ & $<0.001$ \\
\hline Model 3 & $-0.10(0.02)$ & $<0.001$ \\
\hline \multicolumn{3}{|l|}{ Weight (kg) } \\
\hline Model 1 & $0.33(0.04)$ & $<0.001$ \\
\hline Model 2 & $0.28(0.04)$ & $<0.001$ \\
\hline Model 3 & $0.30(0.04)$ & $<0.001$ \\
\hline \multicolumn{3}{|l|}{ MICE } \\
\hline Fat mass (g) & B (SE) & $p$ \\
\hline Model 1 & $0.14(0.11)$ & 0.24 \\
\hline \multicolumn{3}{|l|}{ Body fat (\%) } \\
\hline Model 1 & $0.11(0.19)$ & 0.55 \\
\hline \multicolumn{3}{|l|}{ Lean mass (g) } \\
\hline Model 1 & $0.2(0.07)$ & 0.01 \\
\hline \multicolumn{3}{|l|}{ Body lean (\%) } \\
\hline Model 1 & $-0.07(0.17)$ & 0.67 \\
\hline \multicolumn{3}{|l|}{ Weight (g) } \\
\hline Model 1 & $0.34(0.16)$ & 0.04 \\
\hline
\end{tabular}

Model 1 was unadjusted (humans and mice). Model 2 was adjusted for age. Model 3 was adjusted for age plus physical activity, number of morbidities, smoking status, and source of income.

\subsection{Circulating BCAAs and Diet}

The association between energy, macronutrient intakes, and circulating BCAAs were similar in both mice and humans. Higher intakes of protein were significantly associated with higher circulating BCAAs and while similar trends occurred for energy intake, this was not statistically significant. Similarly, the negative relationship between BCAAs and carbohydrates showed a similar pattern in both species, with the correlation stronger in mice compared to humans. Fat intake was positively associated with circulating BCAAs in humans $(p=0.016)$, with a similar-albeit non-significant-trend in mice (Figure 2). Correlation matrices of individual BCAAs show similar relationships with energy and macronutrient intakes in both mice and men. With the exception of carbohydrate intake, all other nutrient intakes were positively correlated with valine, isoleucine, and leucine. As with total BCAA levels, individual amino acids were most strongly correlated with protein intake in mice, a result consistent with our previous findings [4]. 


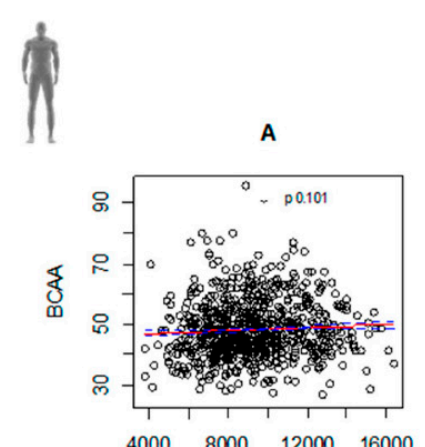

$4000 \quad 8000 \quad 12000 \quad 16000$

Energy (kJ)

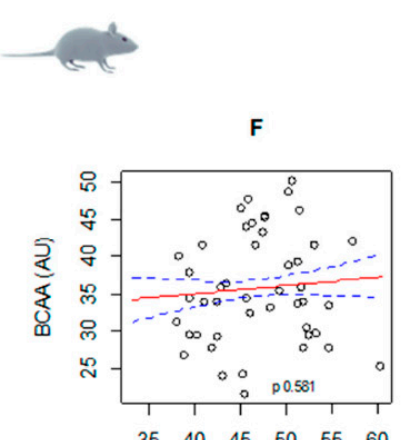

Energy $(\mathrm{kJ})$

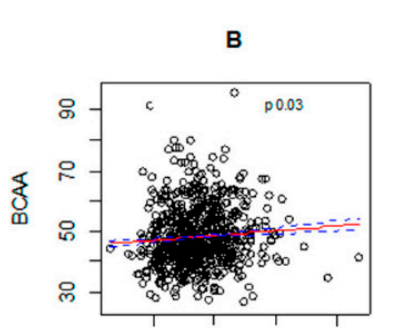

1000200030004000

Protein (kJ)

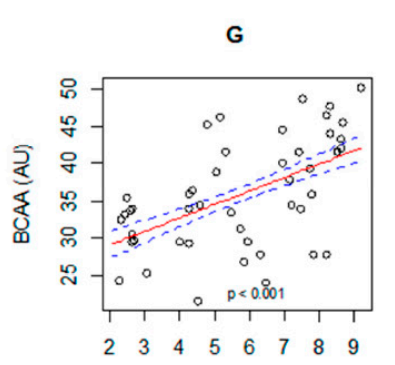

Protein (kJ)

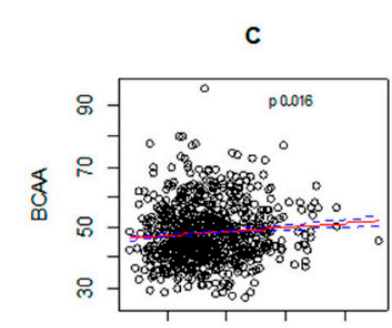

2000400060008000

Fat (kJ)

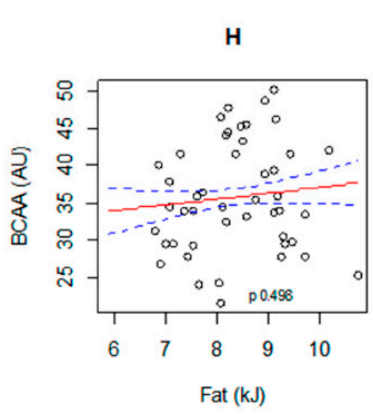

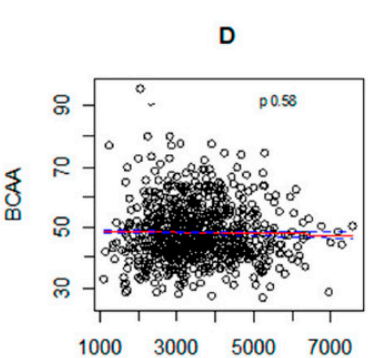

Carbohydrate (kJ)

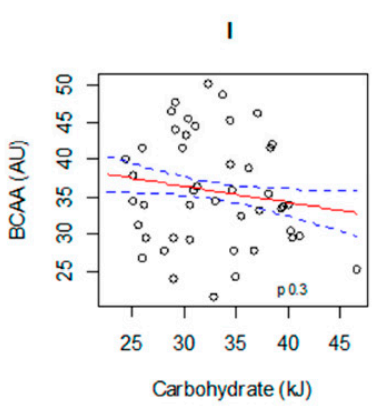

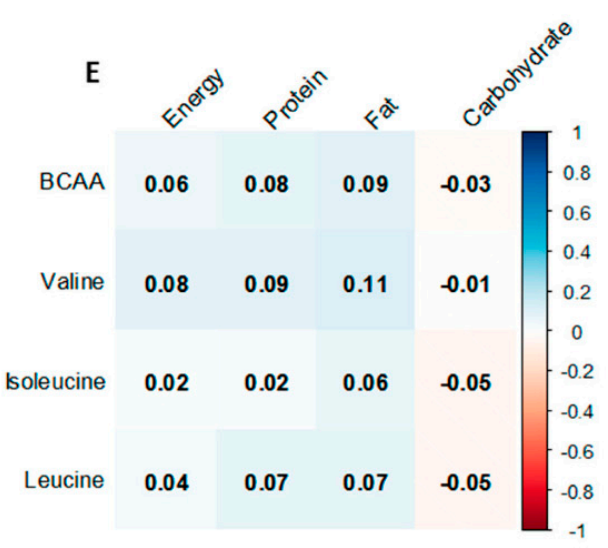

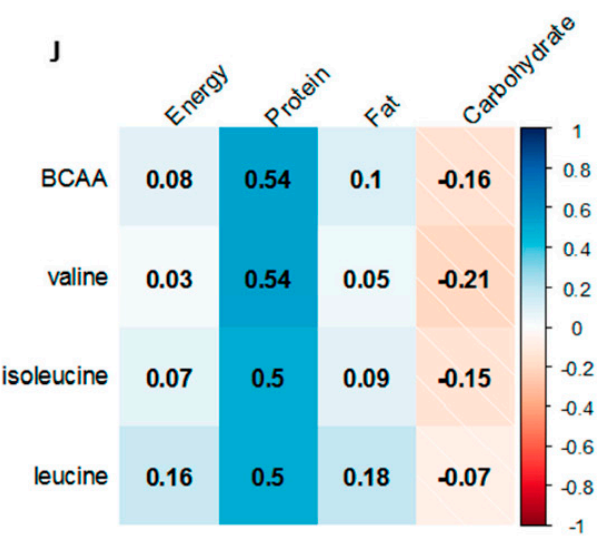

Figure 2. Circulating BCAA (branched chain amino acid) vs. nutrient intake in older men (A-E) and mice (F-J). Red lines represent fitted values and blue dotted lines represent $95 \%$ confidence intervals. In both humans and mice, protein intake was associated with higher circulating BCAAs (B,G). Men who consumed a diet high in fat were more likely to have higher circulating BCAAs (C). Correlation matrices show a similar pattern of correlation between dietary intakes and individual BCAAs in both men (E) and mice (J). 


\section{Discussion}

There has been limited research into the relationship between blood levels of BCAAs and aging. Studies have suggested that BCAAs decline with old age [24-26]. There have also been studies of the relationship between BCAAs and frailty or sarcopenia, which are classic age-related syndromes, some of which have shown an association with low BCAA levels [27-30]. Although it is unclear exactly why BCAAs decline with age, age-related changes in muscle protein metabolism, such as an imbalance in the rate of protein synthesis and breakdown, increased resistance to anabolic factors, changes in levels of physical activity, and an overall reduction in dietary intake of protein may be contributing factors [31,32]. Here, we demonstrate that total BCAA levels and individual levels of isoleucine, leucine, and valine, not only declined with age in humans, but were also linked with body composition, with those with higher circulating BCAA levels more likely to be carrying more weight and fat mass. Because the increase in fat mass outweighed the increase in lean mass, there was a corresponding increase in body fat percentage and a decrease in body lean percentage. Strikingly, we found that the association between BCAA and body composition markers were similar in mice models and in the human cohort of older males.

In terms of the associations between dietary intakes and circulating BCAA levels, as expected, a clear association was demonstrated between protein intake and circulating BCAA levels in mice. This association was not as clear in older men, though it followed the same trend. Plasma BCAA levels are likely to reflect long-term protein intake [33], yet high protein intake can increase circulating concentrations of BCAAs, with up to $80 \%$ of consumed BCAAs reaching circulation [34,35]. A number of factors, such as insulin resistance [36], cardiovascular disease [37], body composition [7], and protein sources [5], can also influence circulating BCAA levels. In the current study, we investigated the correlation between protein and BCAA levels in mice kept in a well-controlled environment for their whole life, whereas for the human cohort, dietary intake was estimated through diet history interviews, which may also explain the weaker association between protein intake and circulating BCAAs in the human cohort. Another potential explanation for the difference in the strength of association between protein intake and BCAA levels in mice and humans was the source of protein: mice were provided with casein protein, whereas protein sources were varied in the human cohort [15].

In recent years, BCAAs have received increased attention for their role in muscle synthesis and as a potential intervention option to improve muscle quality; a number of clinical studies have pointed to a crucial role of BCAAs in tackling muscle loss in older individuals. It has been suggested that the increase of protein or amino acids alone (as opposed to combining high protein or amino acids with high carbohydrate and/or energy) should result in better outcomes in older individuals [31,38]. The current study indicates that carbohydrate intakes have a negative association with circulating BCAA levels in both mice and humans.

The current study has several strengths worth mentioning: (1) data from a large sample of community-dwelling men and a large sample of mice on a well-defined diet and tightly controlled environmental conditions were used in our analyses; (2) the use of gold-standard methodology to obtain body-composition measures in humans (DXA) and in mice (EchoMRI); and (3) the dietary assessment method used (diet history) and frequent food intake measurements in mice. It is also worth mentioning the limitations of the current study: firstly, causal association cannot be established from the human cohort results; secondly, there may be other factors that play an important role in the relationship between dietary intake, BCAA levels, and body composition, such as genetic background and long-term dietary intake. Finally, the results may not be applicable to older females.

\section{Conclusions}

This is the first study to investigate the role of BCAA levels in large cohorts of mice and humans. Higher protein intakes were associated with higher BCAA levels and higher body weight and fat mass in both species. Further studies are required to elucidate the association between BCAA levels and body composition in older age, but this study adds to the body of evidence showing that mouse 
models can provide valuable insight into the relationship between nutrition and health, which can be translated to humans.

Supplementary Materials: The following are available online at http://www.mdpi.com/2072-6643/11/8/1882/s1, Figure S1: Circulating BCAAs and age, PASE, number of morbidities, smoking status and source of income.

Author Contributions: R.V.R., S.M.S.-B. and D.G.L.C. developed the concepts for this paper. The CHAMP study was designed by R.G.C., V.N., D.J.H., M.J.S., D.G.L.C., L.M.W. and F.M.B. S.M.S.-B., D.G.L.C., and S.J.S. designed the mouse study. S.M.S.-B., T.P., V.C.C., X.C., J.O., V.C.C. and Y.C.K. performed mouse experiments. V.H., A.M.S., A.G., R.G.C., F.M.B., V.N., L.M.W., D.J.H., M.J.S., S.J.S., F.S. and D.G.L.C. collaborated in writing. All authors reviewed and approved the final version of the manuscript. All authors had primary responsibility for final content.

Funding: This research was funded by National Health and Medical Research Council (NHMRC) grant number 301916 and GNT1084267.

Acknowledgments: We thank all the CHAMP's staff and participants for their contributions, Sydney Medical School Foundation and the Ageing, Alzheimer's Institute and Jennie Mackenzie for their support. SSB is supported by the NHMRC Peter Doherty Biomedical Fellowship (GNT1110098) and the University of Sydney SOAR fellowship. RVR was supported by a Charles Perkins Centre Early Career Fellowship from Jennie Mackenzie.

Conflicts of Interest: The authors declare no conflicts of interest.

\section{References}

1. Fontana, L.; Cummings, N.E.; Apelo, S.I.A.; Neuman, J.C.; Kasza, I.; Schmidt, B.A.; Cava, E.; Spelta, F.; Tosti, V.; Syed, F.A.; et al. Decreased consumption of branched chain amino acids improves metabolic health. Cell Rep. 2016, 16, 520-530. [CrossRef] [PubMed]

2. Newgard, C.B.; An, J.; Bain, J.R.; Muehlbauer, M.J.; Stevens, R.D.; Lien, L.F.; Haqq, A.M.; Shah, S.H.; Arlotto, M.; Slentz, C.A.; et al. A Branched-Chain Amino Acid-Related Metabolic Signature that Differentiates Obese and Lean Humans and Contributes to Insulin Resistance. Cell Metab. 2009, 9, 565-566. [CrossRef]

3. Maida, A.; Chan, J.S.; Sjøberg, K.A.; Zota, A.; Schmoll, D.; Kiens, B.; Herzig, S.; Rose, A.J. Repletion of branched chain amino acids reverses mTORC1 signaling but not improved metabolism during dietary protein dilution. Mol. Metab. 2017, 6, 873-881. [CrossRef] [PubMed]

4. Solon-Biet, S.M.; McMahon, A.C.; Ballard, J.W.O.; Ruohonen, K.; Wu, L.E.; Cogger, V.C.; Warren, A.; Huang, X.; Pichaud, N.; Melvin, R.G.; et al. The Ratio of Macronutrients, Not Caloric Intake, Dictates Cardiometabolic Health, Aging, and Longevity in Ad Libitum-Fed Mice. Cell Metab. 2014, 19, 418-430. [CrossRef] [PubMed]

5. Rousseau, M.; Guénard, F.; Garneau, V.; Allam-Ndoul, B.; Lemieux, S.; Pérusse, L.; Vohl, M.C. Associations Between Dietary Protein Sources, Plasma BCAA and Short-Chain Acylcarnitine Levels in Adults. Nutrients 2019, 11, 173. [CrossRef] [PubMed]

6. Solon-Biet, S.M.; Cogger, V.C.; Pulpitel, T.; Wahl, D.; Clark, X.; Bagley, E.E.; Gregoriou, G.C.; Senior, A.M.; Wang, Q.P.; Brandon, A.E.; et al. Branched-chain amino acids impact health and lifespan indirectly via amino acid balance and appetite control. Nat. Metab. 2019, 1, 532-545. [CrossRef]

7. Lynch, C.J.; Adams, S.H. Branched-chain amino acids in metabolic signalling and insulin resistance. Nat. Rev. Endocrinol. 2014, 10, 723-736. [CrossRef]

8. Cummings, N.E.; Williams, E.M.; Kasza, I.; Konon, E.N.; Schaid, M.D.; Schmidt, B.A.; Poudel, C.; Sherman, D.S.; Yu, D.; Apelo, S.I.A.; et al. Restoration of metabolic health by decreased consumption of branched-chain amino acids. J. Physiol. 2017, 596, 623-645. [CrossRef]

9. Wang, T.J.; Larson, M.G.; Vasan, R.S.; Cheng, S.; Rhee, E.P.; McCabe, E.; Lewis, G.D.; Fox, C.S.; Jacques, P.F.; Fernandez, C.; et al. Metabolite Profiles and the Risk of Developing Diabetes. Nat. Med. 2011, 17, 448-453. [CrossRef]

10. Shah, S.H.; Crosslin, D.R.; Haynes, C.S.; Nelson, S.; Turer, C.B.; Stevens, R.D.; Muehlbauer, M.J.; Wenner, B.R.; Bain, J.R.; Laferrere, B.; et al. Branched-chain amino acid levels are associated with improvement in insulin resistance with weight loss. Diabetologia 2012, 55, 321-330. [CrossRef]

11. Zheng, Y.; Li, Y.; Qi, Q.; Hruby, A.; Manson, J.E.; Willett, W.C.; Wolpin, B.M.; Hu, F.B.; Qi, L. Cumulative consumption of branched-chain amino acids and incidence of type 2 diabetes. Int. J. Epidemiol. 2016, 45, 1482-1492. [CrossRef] 
12. Bifari, F.; Nisoli, E. Branched-chain amino acids differently modulate catabolic and anabolic states in mammals: A pharmacological point of view. Br. J. Pharmacol. 2017, 174, 1366-1377. [CrossRef]

13. D'Antona, G.; Ragni, M.; Cardile, A.; Tedesco, L.; Dossena, M.; Bruttini, F.; Caliaro, F.; Corsetti, G.; Bottinelli, R.; Carruba, M.O;; et al. Branched-Chain Amino Acid Supplementation Promotes Survival and Supports Cardiac and Skeletal Muscle Mitochondrial Biogenesis in Middle-Aged Mice. Cell Metab. 2010, 12, 362-372. [CrossRef]

14. Cumming, R.G.; Handelsman, D.; Seibel, M.J.; Creasey, H.; Sambrook, P.; Waite, L.; Naganathan, V.; Le Couteur, D.; Litchfield, M. Cohort Profile: The Concord Health and Ageing in Men Project (CHAMP). Int. J. Epidemiol. 2009, 38, 374-378. [CrossRef]

15. Waern, R.V.; Cumming, R.G.; Blyth, F.; Naganathan, V.; Allman-Farinelli, M.; Le Couteur, D.; Simpson, S.J.; Kendig, H.; Hirani, V. Adequacy of nutritional intake among older men living in Sydney, Australia: Findings from the Concord Health and Ageing in Men Project (CHAMP). Br. J. Nutr. 2015, 114, 812-821. [CrossRef]

16. Burke, B. The dietary history as a tool in research. J. Am. Diet. Assoc. 1947, 23, 1041-1046.

17. Rosilene, W.; Cumming, R.; Travison, T.; Blyth, F.; Naganathan, V.; Allman-Farinelli, M.; Hirani, V. Relative validity of a diet history questionnaire against a four-day weighed food record among older men in Australia: The Concord Health and Ageing in Men Project (CHAMP). J. Nutr. Health Aging 2015, 19, 603-610. [CrossRef]

18. Washburn, R.A.; Smith, K.W.; Jette, A.M.; Janney, C.A. The physical activity scale for the elderly (PASE): Development and evaluation. J. Clin. Epidemiol. 1993, 46, 153-162. [CrossRef]

19. Wahl, D.; Solon-Biet, S.M.; Wang, Q.P.; Wali, J.A.; Pulpitel, T.; Clark, X.; Raubenheimer, D.; Senior, A.M.; Sinclair, D.A.; Cooney, G.J.; et al. Comparing the Effects of Low-Protein and High-Carbohydrate Diets and Caloric Restriction on Brain Aging in Mice. Cell Rep. 2018, 25, 2234-2243. [CrossRef]

20. Patsch, C.; Challet-Meylan, L.; Thoma, E.C.; Urich, E.; Heckel, T.; O’Sullivan, J.F.; Grainger, S.J.; Kapp, F.G.; Sun, L.; Christensen, K.; et al. Generation of vascular endothelial and smooth muscle cells from human pluripotent stem cells. Nat. Cell Biol. 2015, 17, 994. [CrossRef]

21. Chambers, J.M. Chapter 4 of Statistical Models in S. In Linear Models; Wadsworth \& Brooks/Cole: Pacific Grove, CA, USA, 1992.

22. Wilkinson GNaR, C.E. Symbolic descriptions of factorial models for analysis of variance. Appl. Stat. 1973, 22, 392-399. [CrossRef]

23. Wei, T.; Simko, V. R Package "Corrplot": Visualization of a Correlation Matrix (Version 0.84); R Foundation for Statistical Computing: Vienna, Austria, 2017.

24. Chaleckis, R.; Murakami, I.; Takada, J.; Kondoh, H.; Yanagida, M. Individual variability in human blood metabolites identifies age-related differences. Proc. Natl. Acad. Sci. USA 2016, 113, 4252-4259. [CrossRef]

25. Kouchiwa, T.; Wada, K.; Uchiyama, M.; Kasezawa, N.; Niisato, M.; Murakami, H.; Fukuyama, K.; Yokogoshi, H. Age-related changes in serum amino acids concentrations in healthy individuals. Clin. Chem. Lab. Med. 2012, 50, 861-870. [CrossRef]

26. Oja, S.S.; Kemppainen, K.; Mero, A.A.; Pitkänen, H.T.; Seppä, J.M. Serum amino acid concentrations in aging men and women. Amino Acids 2003, 24, 413-421.

27. Calvani, R.; Picca, A.; Marini, F.; Biancolillo, A.; Gervasoni, J.; Persichilli, S.; Primiano, A.; Coelho-Junior, H.; Bossola, M.; Urbani, A.; et al. A Distinct Pattern of Circulating Amino Acids Characterizes Older Persons with Physical Frailty and Sarcopenia: Results from the Biosphere Study. Nutrients 2018, 10, 1691. [CrossRef]

28. Adachi, Y.; Ono, N.; Imaizumi, A.; Muramatsu, T.; Andou, T.; Shimodaira, Y.; Nagao, K.; Kageyama, Y.; Mori, M.; Noguchi, Y.; et al. Plasma amino acid profile in severely frail elderly patients in Japan. Int. J. Gerontol. 2018, 12, 290-293. [CrossRef]

29. Moaddel, R.; Fabbri, E.; Khadeer, M.A.; Carlson, O.D.; Gonzalez-Freire, M.; Zhang, P.; Semba, R.D.; Ferrucci, L. Plasma Biomarkers of Poor Muscle Quality in Older Men and Women from the Baltimore Longitudinal Study of Aging. J. Gerontol. A Biol. Sci. Med. Sci. 2016, 71, 1266-1272. [CrossRef]

30. Ter Borg, S.; Luiking, Y.C.; van Helvoort, A.; Boirie, Y.; Schols, J.; de Groot, C. Low Levels of Branched Chain Amino Acids, Eicosapentaenoic Acid and Micronutrients Are Associated with Low Muscle Mass, Strength and Function in Community-Dwelling Older Adults. J. Nutr. Health Aging 2019, 23, 27-34. [CrossRef]

31. Fujita, S.; Volpi, E. Amino acids and muscle loss with aging. J. Nutr. 2006, 136 (Suppl. 1), 277S-280S. [CrossRef] 
32. Ottestad, I.; Ulven, S.M.; Øyri, L.K.L.; Sandvei, K.S.; Gjevestad, G.O.; Bye, A.; Sheikh, N.A.; Biong, A.S.; Andersen, L.F.; Holven, K.B. Reduced plasma concentration of branched-chain amino acids in sarcopenic older subjects: A cross-sectional study. Br. J. Nutr. 2018, 120, 445-453. [CrossRef]

33. Würtz, P.; Mäkinen, V.P.; Soininen, P.; Kangas, A.J.; Tukiainen, T.; Kettunen, J.; Savolainen, M.J.; Tammelin, T.; Viikari, J.S.; Rönnemaa, T.; et al. Metabolic Signatures of Insulin Resistance in 7098 Young Adults. Diabetes 2012, 61, 1372-1380.

34. Layman, D.K.; Baum, J.I. Dietary Protein Impact on Glycemic Control during Weight Loss. J. Nutr. 2004, 134, 968S-973S. [CrossRef]

35. Rietman, A.; Schwarz, J.; Tomé, D.; Kok, F.J.; Mensink, M. High dietary protein intake, reducing or eliciting insulin resistance? Eur. J. Clin. Nutr. 2014, 68, 973. [CrossRef]

36. Gannon, N.P.; Schnuck, J.K.; Vaughan, R.A. BCAA Metabolism and Insulin Sensitivity—Dysregulated by Metabolic Status? Mol. Nutr. Food Res. 2018, 62, 1700756. [CrossRef]

37. Du, X.; You, H.; Li, Y.; Wang, Y.; Hui, P.; Qiao, B.; Lu, J.; Zhang, W.; Zhou, S.; Zheng, Y.; et al. Relationships between circulating branched chain amino acid concentrations and risk of adverse cardiovascular events in patients with STEMI treated with PCI. Sci. Rep. 2018, 8, 15809. [CrossRef]

38. Wolfe, R.R. Branched-chain amino acids and muscle protein synthesis in humans: Myth or reality? J. Int. Soc. Sports Nutr. 2017, 14, 30. [CrossRef]

(C) 2019 by the authors. Licensee MDPI, Basel, Switzerland. This article is an open access article distributed under the terms and conditions of the Creative Commons Attribution (CC BY) license (http://creativecommons.org/licenses/by/4.0/). 